\title{
Role of Individual Learning Pathways in Non-Threatening Teaching and Learning Environment Development
}

\author{
Elena A. Makarova \\ Taganrog Institute of Economics and Management, 45 Petrovskaya, Taganrog 347900, Russian Federation \\ *Corresponding Author: makarova.h@gmail.com
}

Copyright (C) 2014 Horizon Research Publishing. All rights reserved.

\begin{abstract}
The paper covers a diverse range of topics, the areas of interest for this particular paper include (a) knowledge structures and mental models, (b) problem solving processes, (c) metacognition, (d) skill acquisition, (e) individual learning styles, and (f) transfer of learning. The following brief synopsis of the paper serves to illustrate the focus of this work, validates current practice in higher education, and identifies a set of principles that can help instructional designers address individual cognitive learning goals.
\end{abstract}

Keywords Individual Learning Pathway, Psychologically Comfortable Educational Environment, Learning Styles, Student-Centered Education, Knowledge Structure, Mental Models, Metacognition

"Any experience that results from the interaction of an individual with his or her environment-and in which the individual manipulates and shapes that environment-can be called art. The quality of this interaction is influenced by teachers' decisions, their timing, their choice of tasks, even the use of their voices. When all this happens, when everything flows, ...teaching ceases to be an action and becomes art" [1].

\section{Introduction}

How often do we, teachers, impose learning pathways upon students which do not meet their needs, or fit their expectations? How many times have we invested in technology, learning and teaching environment and curricula that is simply a waste of time and resources?

The given article focuses on Russian students (both undergraduate and graduate) and also on university instructors whose job is to get students ready for individual studies. Special courses for tutors have to be scheduled, and the curriculum for such courses has to be designed as an ultimate practical output of theoretical study.

The paper is aimed at the creation and development of non-threatening and psychologically comfortable educational environment at Russian Universities. Nowadays, education is based on the group method which is defective and inefficient as students with different abilities and knowledge levels from different educational and cultural backgrounds are grouped and taught in the same way. Traditionally, students are grouped in the very first year of study and stay in the same group for the period of time they need to complete their degree. They have to follow the same curriculum and schedule; they are delivered the same lectures and take the same exams no matter what majors they take. All of them take the same level standardized and unified tests notwithstanding their lack of knowledge or different educational, social or cultural backgrounds. Group method of teaching and learning has been traditional for Russian system of education for years, but nowadays it causes a lot of problems [2]. These problems include the inability of learners to follow the instructions, to make connections between new information and their existing knowledge structure, to use the knowledge they apparently possess, and transfer this knowledge to new problems and situations [3].

Many freshmen live through hard times; they are under a lot of pressure and experience psychological difficulties that may lead to stress or even worse to dropping off. The phenomenon in teaching and learning that negative emotions greatly hamper learning is widely known. Individualization of education has the magical effect of getting rid of these negative emotions. These educational problems are, in part at least, instructional design problems [4]. Educators have limited knowledge of how best to meet the individual needs of their students, how to expose learners to new knowledge using the advantage of their individual learning styles and how to provide learners with practice in applying and transferring their knowledge. Hopefully, the given research would provide theoretical and empirical evidence that these educational problems can and should be resolved in Russian Universities.

\section{Education Research Areas}

Education researchers, for the most part, have shown little 
interest in science-based research of instructional design problems. Although studies of cognition by educators are limited, considerable research is being done in other fields (psychology, sociology, socionics, anthropology), the results of which can successfully be transferred to teaching and learning situation. The lack of involvement by the education community is unfortunate because the topics of interest in science are closely aligned with practice of education. For example, in Western Europe, much of the recent research on cognition has focused on topics such as monitoring, individual learning styles, and instructional design based on individual learning paths (trajectories). Psychological studies have been aimed at designing and development of non-threatening and psychologically comfortable educational environment [5]. The findings from these studies also serve to validate contemporary instructional practice in education. For example, in 2010 the Welsh Government decided that every young person in the country should have their own unique Individual Learning Pathway which would lead to approved qualifications. Their pathway must be tailored to their needs, interests and aspirations. However, in the end all of the graduates should meet the same educational standards and pass the same standardized exams. It means they will achieve the same goal, get similar qualifications, but follow different pathways depending on their strengths and weaknesses. At the same time, on the other side of the planet, in Australia, a number of governmental acts were directed at providing effective individual learning pathways to increase the number of working aged Australians who have a formal qualification [6]. To meet these targets existing barriers to entering and participating in vocational education and training will need to be overcome [7]. This fact proves that educators in different countries and even on different continents take a keen interest in improving adult learners' teaching and learning conditions.

In this paper we would like to review existing cognitive science research and works in psychology relevant to education, to help develop an appropriate curriculum based on individual needs of learners. This review is intended to provide a conceptual basis and direction for instructional design in Russian system of education. Besides, the theoretical aspects of the problem should be presented at seminars and conferences for University instructors in order to show the alternative to the current approach to teaching and learning. Moreover, the role of a teacher in the educational process is slightly changing nowadays; the system of tutoring is highly developed in Western European and American Universities. Tutors' responsibilities are to provide opportunities for students to follow their individual learning pathways. They have to function as counselors to advise students and help them choose the best pathway and avoid mistakes in the course of studies.

Besides, the paper provides a better understanding of human competence (and incompetence) and the processes that underlie good thinking and problem solving. Possibly the most exciting research results relevant to education come from studies that compare expert and novice performances in areas such as foreign languages and culture.

Modern science knows different types of individual learning styles. Classification of personal learning types given by B. Leaver should be mentioned here [8]. In this classification he systematized different types of learning preferences (methods of teaching, types of textbooks, forms of information presentation) depending on the socio-cultural peculiarities of learners. She also mentions learning styles and suggests organizing teaching and learning process based on the majority of perception styles in group, but considering the group of risk (minority), too. This individual approach was developed in socionics. B. Leaver suggested two major approaches to education design, which she called "Western" and "Non-Western". As the basis for the western one, there is traditional for western culture educational position of consistent way of thinking, logic, verbal method of information presentation. This system is the most practical, in our opinion, and combines all learning styles into two groups: the ones whose perception is holistic and global, and the ones whose perception is based on components of the whole. The system allows to differentiate students, to explain their differences and to create curricular relevant to these differences.

Current cognitive theory suggests that a key to competent performance lies in the organization of students' learning activity. Possession of a well developed knowledge structure appears to have an influence on performance [9]. As Russia is a country lying between two worlds (Western and Eastern), the type of culture it possesses could be called a mixed one. It influences learning styles, too. Nevertheless, Russian system of education has been leaning to Western educational position lately.

Major goal of instructors is to help students develop an understanding of Western system of education and its key concepts. Based on what is known about cognitive styles, instruction should help students gain an expert-like position in educational environment based on the knowledge how the system works. Instruction may help students resolve any ambiguities about the system and clarify the components and their relationships within the system. Students should be provided with conceptual knowledge that is based on qualitative, causal models of the system's work. They should also be taught how to develop and use the system to understand and interact with other systems.

\section{Knowledge Structures and Mental Models}

The key word here is competence, the observable or measurable pattern of knowledge, skills, abilities, behaviors and other characteristics critical to successful future job performance of a graduate. Competencies specify what a student needs to know to do successfully in his future professional career. Competence is a dynamic concept; it can't be reached once and forever. The process of acquiring competence is a never-ending and absolutely individual one. 
Current cognitive theory suggests that a key to competent performance lies in the organization of one's knowledge. Working memory can only hold a finite amount of information [10]. To work around the limits of working memory, people organize their memory into "packages" that contain related information [11]. Due to their memory organization, experts are able to possess a large knowledge base that is organized into elaborate, integrated structures while novices possess less knowledge that is not as coherently organized.

Several studies support the theory that memory organization is a major factor in competent performance [12]. A study by Egan and Schwartz (1979) is directly relevant to technology education. In this study, expert and novice subjects were briefly shown drawings and were asked to reconstruct the drawings from memory. When presented with drawings of actual devices, the experts, as expected, were able to recall significantly more of the drawing than the novices. However, when shown drawings with random and illogical placement of components, the experts performed no better than the novices. This study suggests that the memory of expert technicians is based on conceptual patterns which enable them to recall portions of the drawings as a group of information rather than as individual components [13], [14].

The concept of knowledge organization is based on schema theory which suggests that unconscious mental structures underlie all human knowledge and skill. Schemata contain abstracted generic knowledge that has been organized into new qualitative knowledge structures. For example, most adults have a "generic" schema for grocery shopping. In a grocery store we expect to find certain things such as a cart to carry our purchases, several aisles of packaged foods, a freezer for frozen foods, a meat counter, and a checkout area. No matter what grocery store we enter, we expect to find these types of things. This grocery store schema is used to organize our knowledge and experiences about grocery stores and to facilitate the process of preparing a shopping list and locating items in a store. For example, when preparing a shopping list we can mentally walk through the aisles of the store to help us recall the food items on the shopping list that we need.

Possession of a well developed knowledge structure appears to have an influence on performance. Brewer and Nakamura (1984) identify five basic processes through which knowledge structures can facilitate performance. Knowledge structures influence the amount of attention given to information which can lead to better memory development [15].

Knowledge structures serve as a framework in memory that helps retain new information. In other words, knowledge structures serve as an "anchor" that connects new information to an existing knowledge structure [16].

Learning takes place when information in an existing knowledge structure interacts with new information to form a memory representation that is a combination of the old and new structures. This is called background knowledge; a kind of previous experience of a person kept in his/her memory till it is needed.

Knowledge structures facilitate the process of retrieving information from memory. Several studies support the hypothesis that memory recall is greater when appropriate knowledge structures exist [17]. Knowledge structures are used to edit the information that is retrieved from memory.

In addition to having their knowledge better organized than novices, experts are able to use their knowledge to form mental and physical representations of situations or problems that confront them. The types of structure that appear most relevant for technology education are mental representations based on physical systems and objects which are also called "causal mental models" [18], [19]. Mental models help to predict or explain our interactions with people and equipment. These models can also improve performance on cognitive tasks such as problem solving and decision making [20].

\section{Problem Solving Processes}

Experts and novices differ in the way they attend to problem information. Experts are able to direct their attention to appropriate aspects of a problem through the use of their large knowledge base (background knowledge) while novices' attention seems to be guided by their senses [21]. Consequently, experts are able to confine their attention to smaller portions of a problem space and process only the information that is most likely to help solve the problem. In contrast, novices are less able to discriminate between relevant and irrelevant information, obtain less useful information for a given amount of effort, and do not efficiently reduce the size of the problem space they are considering. Because experts have extensive experience and knowledge, few features in a problem are unique or unfamiliar to them. As a result, experts can focus their attention on the few features that may be less familiar to them while novices, due to their limited knowledge and experience, find that many features of a problem are unique and must be fully explored [22]. Consequently, novices must process more information than experts during problem solving and decision making which occupies the novices' limited mental resources and reduces their ability to focus on the truly relevant aspects of the problem.

Differences also exist between experts and novices in relation to their ability to process information [23]. Novices mentally manipulate information through the use of controlled processes which involve relatively slow, conscious processing of information in working memory. In contrast, experts process information through the use of highly developed automatic processing skills. These processes are over-learned skills that involve fast, automatic processing of information without the need for conscious control. This characterization of expert processing of information helps explain the apparent "power" of experts as they approach and solve problems.

Experts are also able to effectively use their knowledge 
and skills to select and obtain appropriate information, to accurately interpret that information, and to control their actions through intelligent planning. In a study of troubleshooting expertise, Johnson (1987) observed little difference between expert and novice troubleshooters in their ability to acquire and interpret information, to perform procedural tests, or to generate and evaluate hypotheses. The major difference between expert and novice troubleshooters was in the types of information they acquired, the types of procedural tests they performed, and the types of hypotheses they generated. In other words, the primary difference between expert and novice troubleshooters is their ability to identify critical areas of a problem which result in "smarter" decisions being made regarding the type of information to look for and the logical locations of faults.

It is not surprising that experts approach problems much differently than novices [24], [25], [26], [27]. Experts evaluate problem symptoms thoroughly before selecting a strategy, incorporate more powerful methods, and are not dependent upon a single strategy to facilitate the problem solving process [28]. In contrast, novices tend to jump right into a problem solving without thinking, rely on weak strategies, and lean toward one favorite problem solving strategy.

The ability to select an appropriate strategy is an essential element of the problem solving process. Weak strategies, such as visual inspection, can only find the most symptomatic faults, and a strict topographic search can easily miss a problem. Experts are generally able to use more powerful strategies and change their strategic approaches if necessary. Novices tend to use weak strategies and then make them even less powerful by overusing them. For example, novices have been observed checking the continuity of every conductor or component in the system [29] and checking a switch two or three times using the same test that was previously unproductive [30].

\section{Metacognition}

Cognitive psychologists have identified at least three types of knowledge: (a) declarative knowledge, (b) procedural knowledge, and (c) strategic knowledge. Declarative knowledge consists of the facts, concepts, and principles one knows in any domain of knowledge. Procedural knowledge involves knowing how to perform various cognitive processes and physical actions. Strategic knowledge, or what is often called metacognition, refers to one's awareness of their own thinking processes used to perform specific tasks. Metacognition involves the planning that takes place before engaging in a thinking activity, regulation of one's thinking during the activity, and evaluation of the appropriateness of one's thinking performance upon the completion of the activity. Metacognition includes strategies such as self-monitoring, advance planning, self-checking, questioning, summarizing, predicting, generating alternatives, and evaluating learning.
Metacognition is an important factor in the field of intelligence, learning, problem solving and decision making. Brown (1978) states that "the ability to monitor one's own understanding... is an essential pre-requisite for all problem solving ability" [31]. Bransford (1979) extends this idea a step further when he states that "the ability to plan and evaluate our own learning strategies seems to be a hallmark of intelligent activity" [32:244].

There appears to be a growing consensus among researchers and teachers that it is beneficial to explicitly and directly teach students both the concept of metacognition and the use of metacognitive processes. When using direct instruction, teachers should explicitly teach metacognitive strategies and skills by explaining not only what the strategy is, but also how, when, where, and why the strategy should be employed.

Reciprocal teaching is a very successful instructional approach for teaching reading that makes thinking skills explicit [33]. This approach begins with the teacher modeling the desired metacognitive processes for a small group of students. First, both the teacher and the students read a paragraph, then the teacher asks questions, summarizes what was read, and makes predictions about what would happen in the next paragraph. As the students became more familiar with the process, they gradually take on the role of "teacher" and begin directing questions to the other students who must summarize the text and make predictions. Through this approach, the teacher explicitly models the desired processes for the students who then become more aware of those processes and slowly begin to use them to make learning easier.

Instructional models such as reciprocal teaching have great potential for helping technology students improve their thinking skills. Glass studied pairs of students who used a "thinking aloud" strategy while solving technological problems and found that the instructional approach had a positive impact on students' metacognitive abilities. While further study is needed, it appears that directly teaching metacognitive skills can improve student's overall thinking performance [34].

\section{Individual Learning Styles}

The term "learning styles" was introduced to define individual differences in learning activities in higher education environment. Learning style is a peculiar individual manner of information perception in learning activity, steady methods of interaction between a student and educational environment, the part of which the student is. This term appeared in the 1970s and characterized typical for a particular student approach to learning. In real life teaching and learning, teachers mostly deal with students who use mixed styles in educational situations (sometimes with certain preferences). There are several levels of learning styles (styles of coding and decoding information, styles of perceptional attitudes to reality etc.), each of them growing 
from the previous ones. The system of levels can be called hierarchical.

It should be admitted that the multitude of styles and interaction between them causes more problems in teaching. But it can lead to integrated description of style behavior of a particular learner and a new concept of personal learning style is introduced. Each person perceives (understands and explains) the world differently from other people based on the background knowledge which is idiosyncratic and learning style which is personal.

Background knowledge is a very important concept in the framework of cognitive theory as it defines the world knowledge that the student has already acquired. The new experience is usually compared to the experiences already stored in the memory that helps to better understand what is going on. The role of background knowledge has been formalized in schema theory [35], [36], [37]. Any information either spoken or written does not by itself carry meaning. Rather, it only provides directions for students which help construct meaning from their own, previously acquired knowledge. We can say that comprehension is an interactive process between the student's background knowledge and the information to be learned. Efficient assimilation requires the ability to relate the information to one's own knowledge. For example, let's consider a foreign language learner. For learners reading at the limits of their linguistic abilities, "if the topic... is outside of their experience or base of knowledge, they are adrift on an unknown sea". Readers activate an appropriate schema against which they try to give a text a consistent interpretation. However, one potential source of reading difficulties may be that the reader has a consistent interpretation from the text, but it may not be the one intended by the author. What is understood from the text is a function of the particular schema that is activated at the time of processing, that is, reading the text. When faced with unfamiliar topics, some students may overcompensate for absent schemata by reading in a slow, text-bound manner; other students may overcompensate by wild guessing [38]. Both strategies inevitably result in comprehension difficulties. For example, students in an English classroom were given a very difficult text in English that described the process of processing papers in the office. Only some students who were familiar with the procedure could comprehend what the text was about. The rest of the class gave different interpretations depending on their background knowledge which deviated from the original text.

When we consider personal learning styles, we assume that there is certain integration between different levels of style behavior - styles of coding and processing information, problem solving, decision making and attitude to the world around. In fact, whatever style we are going to consider, it includes integrated mental experience, problem solving strategies, methods of information perception and its processing, besides learning attitudes. So we can say that personal learning style is formed as a result of different level style behavior integration (including cognitive styles). The essence of individual approach and student-centered education consists in personal differences of students as the most important resources for their further effective and efficient learning. The most acute problem in Russian education is the conflict between learners' individual styles and group methods of education as the major method in Russian higher educational system. We believe that certain changes are necessary in order to restructure the whole system of teaching methods, information presentation manner and instructor behavior so that they benefit students' individual preferences in teaching and learning. It also means that students are given as much time for information processing as they need.

In traditional education in Russia individual differences in learning styles are ignored. It causes a lot of psychological problems along with low performance and poor results at the exams, especially the final ones. As a defective one, this system should be changed, individual learning styles should be taken into consideration in new Russian educational system, and favorable conditions for each student should be created. The correct solution of the problem should consider the following: the system should be student-centered and conditions for individual learning style development should be created for each student. Besides, students should have freedom of choice in what learning style to choose within the framework of unified educational environment which has to be student-friendly. Simultaneously, learning environment should offer opportunities for students' learning behavior enrichment. Thus the problem of students' individual learning styles consideration turns into a problem of students' learning styles development and correction depending on their mental experience and under the influence of enriched variety of learning styles existing in the educational environment.

\section{Individual Learning Pathways (Trajectories) Choice}

One of the acute problems in education today is its quality; following this problem Russian Universities can meet another important requirement - competitive ability of graduates not only in local, but also in international labor markets. Individual learning pathways are being developed to provide qualitative, tailor-made curriculum for each student, thus developing their creative ability and competences in their future professional activity. Following along the individual learning pathway might give a student a unique opportunity to become a highly competitive specialist in today's global economic environment.

A.V. Khootorskoy (2005) considers individual learning pathways as the way to develop each student's educational potential, which is the set of his/her organizational, intellectual, creative and other innate abilities. The process of these abilities bringing to light can, implementing and further developing can occur while the student follows along his/her individual learning pathway [39]. 
Other scholars see individual learning pathways as a certain sequence of single learning activity components, developed for each student according to their own educational goals, their innate abilities, personal interests, motives. Students can expand beyond the traditional educational options offered to them, including independent research individual or group projects, educational travel, online classes or lectures. Although it involves a lot of self-study activities, students in most cases follow along the individual learning pathways under the supervision, coordination and monitoring of a teacher. Learning pathways may also refer to various specific courses, academic programs, learning experience and opportunities offered by the University satisfying graduation requirements and meet universal graduation standards that students complete individually in their education toward graduation and professional career. Most scholars connect learning pathways with the concept of individual learning styles depending on the personality of each student, learning ability and motivation. Individual leaning pathways generally depend on students' goals.

In a purposeful student-centered program students are allowed to choose, develop and implement their own way to educational standard independently, but with the teacher's support, supervision and didactic attendance. Although a lot has been already done in the field of individual pedagogies, it is still necessary to design specific set of pedagogical tools, strategies and technologies that would provide psychologically comfortable teaching and learning environment for individual learning pathways implementation in real-life teaching and learning. While a learning pathway program is implemented and individual possibilities are available for students they can be combined with traditional academic course, fundamental scientific approach offered by many universities. Students have to earn credits, take exams and get other forms of academic recognition typical to the local high educational system as a whole. If a learning experience is entirely disconnected from the University programs, it may or may not be considered a learning pathway. Anyway, in many cases following the individual learning pathway gives students equal opportunity to meet state educational standards. In this case specially designed evaluating tool set should be presented to grade students' performance and to estimate their competences.

Success in education can be achieved if theoretical and applied aspects of the problem are thoroughly investigated and combined. An activity (creativity) approach has become the starting point for research in the field of learning pathways development and studies. In Russian psychology an activity approach in education was developed by L. Vygotsky [40] and P. Galperin [41]. It is traditionally used as a basis for learning and teaching theories. Practical training can be considered as the ultimate output upon completion of an individual learning pathway. It is proficiency-based professional learning and working experience that should be valued or recognized according to the implementation of theoretical knowledge into practical activity. The criteria for assessment are accomplishments, skills and products of working experience that students gain. In this case we call them competence-based or proficiency-based pathways.

\section{Conclusions}

To wrap it up, individual learning pathway programs are being developed in Russian Universities. It is not a matter of one day, but certain success has been already achieved. Historically, Universities have offered a selection of courses and programs, but students didn't have the opportunity to choose among the options offered judging by their interests, motives, abilities or plans and ambitions for the future professional career. The standard program used to be offered to the group of students notwithstanding the fact that they were from a different cultural or educational background, and some of them couldn't keep up the pace with the others and cope with the program. Now with the individual learning pathways introduction into Russian system of University education students have the opportunity to choose from the options offered and to design their own tailor-made course according to their background knowledge and skills, learning needs, interests, inspiration or ambitions for the future. Although in many Russian Universities learning pathways for different students are still similarly designed, the number and types of educational options available are expanding. In other Universities individual learning pathway is an experimental program existing alongside with the traditional group method of teaching and learning. Students are given greater flexibility as to choose from customized learning experiences that are based on their individual learning styles, needs or interests. Although individual learning pathways design is an innovative trend in Russian education, a number of traditional forms of students' success assessment have been used so far based on some form of predetermined academic expectations or standards, and learning achievement would be evaluated by educators in the form of grades, credits and other forms of academic recognition awarded to students. It means that new assessment kits are supposed to be designed to match this innovative tendency in education. This is going to be educators' major responsibility for the nearest future.

New teaching technologies, educational strategies, new generation of didactic materials and the system of tutoring which allows each student to choose his/her own learning pathway and creates prerequisite for step-by-step development of their personal learning styles appropriate for a certain type and level of education should be developed in order to be mutually complementary with the newly developed tendency of individual learning pathways. Human purposeful behavior usually reflects the structure of the environment where a human being functions. In order to predict this behavior or to model it certain corrections should be done to the environment. In our case, it is necessary to develop non-threatening and psychologically comfortable teaching and learning environment in Russian Universities. 


\section{REFERENCES}

[1] Pugliese, C. Teaching out-of-the-box: Creativity in the classroom. Imagine...International Alliance for Learning Newsletter, June 2005.

[2] Asmanova I.U., Goryachova M.B. Individual educational trajectories in the sphere of mathematics and science.// Modern science success. 2008 - № 4 - pp. 67-68.

[3] Khootorskoy A.V. Personality oriented teaching. How to teach differently? - Moscow: Vlados-Press Publishing House, 2005.

[4] Bransford, J. D., Franks, J. J., Vye, N. J., \& Sherwood, R. D. New approaches to instruction: Because wisdom can't be told. Paper presented at the meeting of the Conference on Similarity and Analogy, Champaign: University of Illinois, 1986.

[5] Mitina L.M. Psychological accompaniment of education. Moscow, 2003.

[6] Skills Australia, 2010, Australian Workforce Futures - a national workforce development strategy, Commonwealth of Australia http://www.skillsaustralia.gov.au/PDFs_RTFs/WWF_strateg y.pdf

[7] Wallace, R. The Enacted Learner Identities Framework: The Potential to Improve VET Delivery, AVETRA 2010, http://avetra.org.au/wp-content/uploads/201064

[8] Leaver B. Teaching the Whole Class. Corwin Press, 1997.

[9] Selevko G.K. Pedagogical technologies on the basis of active, intensified and effective management. - Moscow, 2005.

[10] Miller, G. A. The magical number seven, plus or minus two. Psychological Review, 1956, 63, 81-97.

[11] Chase, W. G., \& Ericsson, K. A. Skill and working memory. In G. Bower (Ed.), The psychology of learning and motivation (pp. 1-58). New York: Academic, 1982.

[12] Chase, W. G., \& Simon, H. A. Perceptions in chess. Cognitive Psychology, 1973, 4, 55-81.

[13] Egan, D. E., \& Schwartz, B. J. Chunking in recall of symbolic drawings. Memory and Cognition, 1979, 7(2), 149-158.

[14] Simon, D. P., \& Simon, H. A. Expert and novice performance in solving physics problems. Science, 1980, 208, 1335-1342.

[15] Brewer, W. F., \& Nakamura, G. V. The nature and functions of schemas. In R. S. Wyer \& T. K. Srull (Eds.), Handbook of social cognition (pp. 110-160). Hillsdale, NJ: Erlbaum, 1984.

[16] Anderson, R. C., Spiro, R. J., \& Anderson, M. C. Schemata as scaffolding for the representation of information in connected discourse. American Educational Research Journal, 1978, $15(3), 433-440$.

[17] Chiesi, H. L., Spilich, G. J., \& Voss, J. F. Acquisition of domain-related information in relation to high and low domain knowledge. Journal of Verbal Learning and Verbal Behavior, 1979, 18(3), 257-273.

[18] deKleer, J., \& Brown, J. Assumptions and ambiguities in mechanistic mental models. Hillsdale, NJ: Erlbaum, 1983.

[19] White, B. Y., \& Frederiksen, J. R. Causal model progressions as a foundation for intelligent learning environments (Report No. 6686). Cambridge, MA: BBN Laboratories, 1987.

[20] Kieras, D. E., \& Bovair, S. The role of a mental model in learning to operate a device. Cognitive Science, 1984, 8(3), 255-273.

[21] Thomas, R. G., Johnson, S. D., Cooke, B., DiCola, C., Jehng, J., \& Kvistad, L. Cognitive science research as a basis for instructional design: Implications for vocational education. Berkeley, CA: National Center for Research in Vocational Education, 1988.

Newell, A., \& Simon, H. A. Human problem solving. Englewood Cliffs, NJ: Prentice-Hall, 1972.

[22] Shiffrin, R. M., \& Dumais, S. T. The development of automatism. In J. R. Anderson (Ed.), Cognitive skills and their acquisition (pp. 111-140). Hillsdale, NJ: Erlbaum, 1981.

[23] Chi, M. T. H., Feltovich, P. J., \& Glaser, R. (). Categorization and representation of physics problems by experts and novices. Cognitive Science, 1981, 5, 121-152; 25. Larkin, J., McDermott, J., Simon, D. P., \& Simon, H. A. Expert and novice performance in solving physics problems. Science, 1980, 208, 1335-1342.

[24] deKleer, J. How circuits work. In D. G. Bobrow (Ed.), Qualitative reasoning about physical systems (pp. 205-280). Cambridge, MA: MIT Press, 1985

[25] Larkin, J., McDermott, J., Simon, D. P., \& Simon, H. A. Expert and novice performance in solving physics problems. Science, 1980, 208, 1335-1342.

[26] Johnson, S. D., Flesher, J. W., Ferej, A., \& Jehng, J. C. Application of cognitive theory to the design, development, and implementation of a computer-based troubleshooting tutor (Report No. 265). Berkeley, CA: National Center for Research in Vocational Education, 1992.

[27] Johnson, S. D., \& Satchwell, R. E. The effect of functional flow diagrams on technical system understanding (Report No. 469). Berkeley, CA: National Center for Research in Vocational Education, 1992.

[28] Johnson, S. D. Knowledge and skill differences between expert and novice service technicians on technical troubleshooting tasks (Report No. 20). St. Paul: University of Minnesota, Training and Development Research Center, 1987. (ERIC Document Reproduction Service No. ED 284 054).

[29] Brown, A. L. Knowing when, where, and how to remember: A problem of metacognition. In R. Glaser (Ed.), Advances in instructional psychology (pp. 77-165). Hillsdale, NJ: Erlbaum, 1978, p. 83.

[30] Bransford, J. D. Acquiring new knowledge and skills. In J. D. Bransford (Ed.), Human cognition: Learning, understanding and remembering (pp. 204-245). Belmont, CA: Wadsworth, 1979.

[31] Palincsar, A. S., \& Brown, A. L. Reciprocal teaching of comprehension-fostering and monitoring activities. Paper presented at the meeting of the American Educational Research Association, New Orleans, 1984 
[32] Glass, A. R. The effects of thinking aloud pair problem solving on technology education students thinking processes, procedures, and problem solutions Unpublished doctoral dissertation. University of Minnesota, St. Paul, Minnesota. 1991.

[33] Bartlett, F.C. Remembering. Cambridge: Cambridge University Press, 1932.

[34] Anderson, J. R. Acquisition of cognitive skill. Psychological Review, 1982, 89, 369-406.

[35] Rumelhart, D.E. Schemata: the Building Blocks of Cognition. In Theoretical Issues in Reading Comprehension, R.J. Spiro, B.C. Bruce and W.J. Brewer (Eds), Hillsdale, NJ: Erlbaum, Lawrence Associates Inc., 1980.
[36] Carrell, P.L. Culture-specific schemata in L2 comprehension. In R. Orem \& J. Haskell (Eds.). Selected papers from the Ninth Illinois TESOL/BE Annual Convention, First Midwest TESOL Conference, pp 123-132. Chicago: Illinois TESOL/BE, 1981.

[37] Khootorskoy A.V. Personality oriented teaching. How to teach differently? - Moscow: Vlados-Press Publishing House, 2005.

[38] Vygotsky, L. Thought and language. Cambridge, MA: MIT Press, 1934/1986.

[39] Galperin, P. I. Stages in the development of mental acts. In M. Cole \& I. Maltzman (Eds.), A handbook of contemporary soviet psychology (pp. 249-273). New York: Basic Books, Inc., 1969. 